\title{
Genetic polymorphism and high detrimental load in natural populations of Drosophila melanogaster from cellar and vineyard
}

\author{
A. González and \\ J. L. Ménsua
}

Departamento de Genética, Facultad de C. Biológicas, Universidad de Valencia, Dr. Moliner, 50. Burjassot, Valencia, Spain.

Two Spanish natural populations of Drosophila melanogaster have been analysed with respect to genetic variability in third chromosome viability. The two populations, although from the same locality, belong to relatively different habitats: the inside of a cellar and a vineyard. The patterns of homozygote and heterozygote viability are similar in both populations. The homozygous detrimental loads estimated are very high and the values for the $D: L$

(detrimental/lethal) ratio close to $\mathbf{2 \cdot 5}$, which is higher than any previously found. The environmental variance of viability, average degrees of dominance of lethal genes and of viability polygenes and effective population sizes were estimated in each population. The mechanisms which could maintain variability in these populations, the causes of the high detrimental loads and the possibility that cellar and vineyard could be two subpopulations of a larger population are discussed.

\section{INTRODUCTION}

Genetic variability with respect to viability in natural populations of Drosophila melanogaster has been studied by many investigators (e.g., Greenberg and Crow, 1960; Mukai and Yamaguchi, 1974; Choi, 1978).

Recent work on natural populations of Drosophila melanogaster indicate that there is a north to south cline in the extent of genetic variability in viability (Mukai and Nagano, 1983; Tachida et al., 1983; Kusakabe and Mukai, 1984b) and that some kind of balancing selection may be operating in southern populations, (although a mutationselection balance operates at the majority of loci).

The adaptedness of a population is a measure of its ability to survive and reproduce in its own environment, which may encompass many niches. Although theoretical aspects of the relation between genetic variability and ecological niche has been extensively analysed (Levene, 1953; Levins and MacArthur, 1966; Levins, 1968), the variability of genes affecting viability in relation to niche parameters has not been studied.

Correspondence should be addressed to: Ana González Garrido, Dpto. Genética. Facultad C. Biológicas, Dr. Moliner, 50, 46100 Burjassot (Valencia), Spain.
This paper presents the patterns of viability, genetic load and population size of a population of Drosophila melanogaster from a cellar and a nearby exterior population in a vineyard in an attempt to measure the extent of genetic variability of viability in Spanish populations and the mechanisms which may operate in its maintenance.

\section{MATERIAL AND METHODS}

Late in October of 1979 a capture of $D$. melanogaster was sampled in two sites with different environmental conditions, a celler and a vineyard separated by $4 \mathrm{~km}$ in Requena (Valencia) in the east of Spain.

\section{Extraction and maintenance of third chromosomes}

Male flies were individually mated to 3 virgin females of the $U b x / S b[T M 2 h c a / C S b]$ strain (the X, II, IV chromosomes and the cytoplasm of $U b x / S b$ flies had been substituted with chromosomes and cytoplasm from the cellar population). A single $U b x$ male fly from each cross was mated again with $3 \mathrm{Ubx} / \mathrm{Sb}$ virgin females in the next generation. Thus, 300 third chromosomes were 
extracted and were maintained, as lines, at $19^{\circ} \mathrm{C}$ in the following way: $15 \mathrm{Ubx}$ males were mated to $15 \mathrm{Ubx} / \mathrm{Sb}$ females. The 15 pairs of flies were distributed at random in 3 vials, establishing 3 replicates. In the next and following generations, 15 males of $U b x$ phenotype were selected at random from the offspring of the 3 replicates, and were mated again with $15 \mathrm{Ubx} / \mathrm{Sb}$ females establishing 3 new replicates.

\section{Estimation of relative viabilities}

Homozygote and heterozygote relative viabilities were estimated as follows: Crosses were made between $4 U b x /+i$ females and $4 U b x /+i$ males with two simultaneous replications in each chromosome line, where " $i$ " indicates line number. In the offspring, $U b x /+i$ and $+i /+i$ flies segregate at an expected ratio of $2: 1$. The relative viabilities of random heterozygotes were estimated in a way similar to the above, combining two successively numbered lines, i.e., $U b x /+i \times U b x /+i_{+1}$ in order to secure random combination of different chromosome lines. As in the case of homozygotes, four-pair matings were conducted with two simultaneous replications. In both cases, four days after the crosses were made, all 8 flies in a vial were transferred to a second vial. Four days after the transfer, all flies were discarded. In both vials, the original and the transferred, all flies were counted 3 times until the 18 th day after the cross or transfer was made. $U b x$ flies and wild type flies from the pair of vials were respectively pooled and considered as a single observation. Relative viability was expressed as the ratio of the number of wild type flies to the number of $U b x$ flies +1 (cf. Haldane, 1956).

The crosses were made at different times (cycles). Fifteen lines were employed per cycle (except two cycles in which 20 were used). The chromosomes for each cycle were chosen at random from chromosomes that originated from males since line numbers were assigned randomly. Homozygote and heterozygote relative viabilities were estimated at the same time within each cycle. Before the analyses were made, all relative viabilities were standardised by cycle to the average heterozygote relative viability of that cycle.

\section{Estimation of environmental variance}

The expected sampling variance $(V s)$ of viability indices is given by the following formula (Mukai et al., 1982a; Mukai and Nagano, 1983):

$$
V s=4 n(m+n) / m^{3}
$$

where " $m$ " and " $n$ " indicate the number of $U b x /+$ and $+/+$ flies emerged, respectively. Thus, environmental variance $\left(V_{E N}\right)$ is given by subtracting the average of the expected sampling variances $\left(\bar{V}_{S}\right)$ of viability indices for respective replicates from the observed error variance $\left(\hat{\sigma}_{E}^{2}\right)$ of viability indices among replicates within lines of crosses.

$$
\hat{V}_{E N}=\hat{\sigma}_{E:}^{2}-\hat{\bar{V}}_{S}
$$

Formula (1) was appropriately modified to take into account the standardization of viability indices.

\section{Estimation of the average degree of dominance for viability polygenes}

The average degree of dominance for viability polygenes was estimated by the regression method of Mukai end Yamaguchi (1974). The expected regression of heterozygote viability $(Y)$ on the sum of the two constituent homozygote viabilities $(X)$ on chromosome basis $\left(\beta_{X, Y}\right)$ estimates the harmonic mean of degree of dominance of newly arisen mutant viability polygenes $\left(\bar{h}_{N}\right)$; at the same time, this gives the average degree of dominance of viability polygenes in an equilibrium population $\left(\bar{h}_{E}\right)$. The regression coefficient of $X$ on $Y\left(\beta_{X . Y}\right)$ gives approximately the inverse of arithmetic mean of the average degree of dominance of newly arisen mutant viability polygenes.

\section{RESULTS}

155 third chromosomes were extracted from the cellar and 145 from the vineyard, and all homozygote and heterozygote relative viabilities were examined.

The cosmopolitan inversions, $\operatorname{In}(3 R) P$ and $\operatorname{In}(3 L) P$ are present in both populations. Their frequencies are: 5.81 per cent for $\operatorname{In}(3 L) P$ and 8.14 per cent for $\operatorname{In}(3 R) P$ in the cellar and 8.00 per cent and 17.33 per cent for $\operatorname{In}(3 L) P$ and $\operatorname{In}(3 R) P$ respectively in the vineyard (González, 1985).

Viability data were collected so as to permit partition of the total variance into (a) the variance between groups of chromosomes tested at the same time (cycles); (b) that between chromosomes within these groups or cycles; (c) that between replicates within the chromosomes.

Table 1 shows a summary of two-level nested anovas which were carried out for homozygote (excluding lethals) and heterozygote viabilities in 
Table 1 Summary of the two-level nested anovas of homozygote and heterozygote viabilities of third chromosomes in cellar and vineyard populations

\begin{tabular}{llllcr}
\hline & & $\mathrm{F}_{\mathrm{C}, \mathrm{CR}}$ & $\mathrm{df}$ & $\mathrm{F}_{\mathrm{CR}, \mathrm{E}}$ & \multicolumn{1}{c}{ df } \\
\hline \multirow{2}{*}{ CELLAR } & Homozygotes & $2 \cdot 2650^{*}$ & 9,107 & $28 \cdot 5899^{* *}$ & 107,117 \\
& Heterozygotes & $0.0001 \mathrm{~ns}$ & 9,145 & $1 \cdot 7276^{*}$ & 145,155 \\
VINEYARD & Homozygotes & $1.4890 \mathrm{~ns}$ & 8,96 & $16 \cdot 9500^{* *}$ & 96,105 \\
& Het zrozygotes & $0.0001 \mathrm{~ns}$ & 8,136 & $1 \cdot 3338^{*}$ & 136,145 \\
\hline
\end{tabular}

$\mathrm{F}:$ Value of $\mathrm{F}$ test

C: Cycles (groups of chromosomes analysed simultaneously)

CR: Chromosomes (within cycles)

E: Error (replicates within cycles)

$*: \mathrm{p}<0.05 ; * *: \mathrm{p}<0.01$

both populations. Significantly greater mean squares are due to chromosomes rather than to replicates in the four groups of analysed data, indicating there is a real genotypic difference between the chromosomes within populations. The differentiation depending on cycles is not significant for homozygotes or heterozygotes in the vineyard nor for the heterozygotes in the cellar. For homozygote viabilities from the cellar, the added variance component among cycles is significant $\left(F_{C, C R}\right)$ at the 5 per cent level: we think that the detected differences, bearing in mind that the number of chromosomes analysed by cycle is not excessively large, are because in given cycles, simply by chance, chromosomes of which the homozygous viabilities are more related to each other than they are to the viabilities of the other cycles may coincide. An additional StudentNewman-Keuls test, comparing the average homozygote viabilities of all cycles from cellar confirmed that all averages could be grouped into the same range.

Linear regression analyses complementing those of variance were carried out to test the relationship between the viabilities of different cycles (groups of chromosomes the viability of which is simultaneously tested) and the time at which the viabilities of these chromosomes are estimated (represented by the generations of maintenance of the chromosomes since these were isolated from nature). There were no significant linear regressions of the homozygote viabilities on the time of maintenance of the chromosomes in either of the populations (table 2). The variance analyses carried out previously showed the unlikeliness of significant lineal regression of heterozygous viabilities on time in either population since:

$$
\begin{aligned}
S S \text { cycles }< & M S \text { (chromosomes) } \\
& \times F\left(1, \sum^{a} n_{i}-a\right)
\end{aligned}
$$

Cellar $1.43 \times 10^{-5}<0.0183 \times F(1,145)$

Vineyard $7.80 \times 10^{-6}<0.0151 \times F(1,136)$

Where:

$n_{i}=$ number of chromosomes per cycle and

$a=$ number of cycles

Table 2 Completed anova table with regression of the homozygote viability of third chromo-

\begin{tabular}{|c|c|c|c|c|c|}
\hline & Source of variation & df & SS & MS & $\mathrm{F}$ \\
\hline & Among cycle & 9 & 1.4103 & $0 \cdot 1567$ & $2 \cdot 2650^{*}$ \\
\hline & Lineal regression & 1 & $0 \cdot 2951$ & $0 \cdot 2951$ & $2 \cdot 1167 \mathrm{~ns}$ \\
\hline \multirow[t]{5}{*}{ CELLAR } & Deviations from regression & 8 & $1 \cdot 1152$ & $0 \cdot 1394$ & $2 \cdot 0153 \mathrm{~ns}$ \\
\hline & Within cycles & 107 & $7 \cdot 4016$ & 0.0691 & \\
\hline & Total & 116 & $8 \cdot 8119$ & & \\
\hline & Among cycle & 8 & 0.8558 & $0 \cdot 1070$ & $1.4890 \mathrm{~ns}$ \\
\hline & Lineal regression & 1 & $0 \cdot 1669$ & $0 \cdot 1669$ & $1.6960 \mathrm{~ns}$ \\
\hline \multirow[t]{3}{*}{ VINEYARD } & Deviations from regression & 7 & 0.6889 & 0.0984 & $1 \cdot 3699 \mathrm{~ns}$ \\
\hline & Within cycles & 96 & $6 \cdot 8961$ & 0.0718 & \\
\hline & Total & 104 & $7 \cdot 7519$ & & \\
\hline
\end{tabular}
somes on the time passed until their analysis. Cellar and vineyard populations

df: Degrees of freedom

SS: Sums of squares

MS: Mean squares

F: Values of $F$ test

*: $\mathrm{p}<0.05$ 


\section{Distributions of relative viabilities}

Relative homozygote and heterozygote viabilities for the third chromosomes are shown in fig. 1. Using the Kolmogorov-Smirnov non parametric test, there were no significant differences between the distribution patterns of the two populations for homozygote or for heterozygote viabilities. The frequency of lethal-carrying chromosomes $(Q)$ was $0.2452(=38 / 155)$ in the cellar and 0.2759 $(=40 / 145)$ in the vineyard.

In the cellar, the average relative viability of homozygotes was $0 \cdot 2452 \pm 0 \cdot 0256$, of homozygotes excluding lethal-carrying chromosomes lines, $0.5194 \pm 0.0255$, and of heterozygotes, $1.0001 \pm$ $0 \cdot 0075$. In the vineyard the average relative viability obtained for homozygotes was $0 \cdot 3678 \pm 0 \cdot 0257$, for homozygotes excluding lethal-carrying chromosome line, $0.4928 \pm 0.0266$, and for heterozygotes, $1 \cdot 0001 \pm 0 \cdot 0070$.

\section{Homozygous load}

The genetic loads caused for genes of viability were calculated using the methods of Greenberg and Crow (1960) (table 3).

\section{Relative viabilities in lethal and semilethal heterozygotes}

(Table 4). The estimate of the average degree of dominance of lethal genes $\left(\bar{H}_{E}\right)$ was made assuming that the lethal genes are distributed on the chromosomes according to a Poisson distribution and that the heterozygous effects of nonhomologous lethal genes are additive. The value estimated for the cellar population was $\left(\hat{H}_{E}=\right.$ 0.0076).

\section{Average degree of dominance of viability polygenes}

All heterozygotes of which the constituent chromosomes have both viability indices larger than 0.6 ( $n=20$ in the cellar; $n=12$ in the vineyard) were used in these estimations which were performed as indicated in materials and methods. For the calculation of the regression coefficients, analyses of variance and covariance were performed to estimate the genetic variances and genetic covariances between the viabilities of random heterozygotes and the sums of the viabilities of the respective

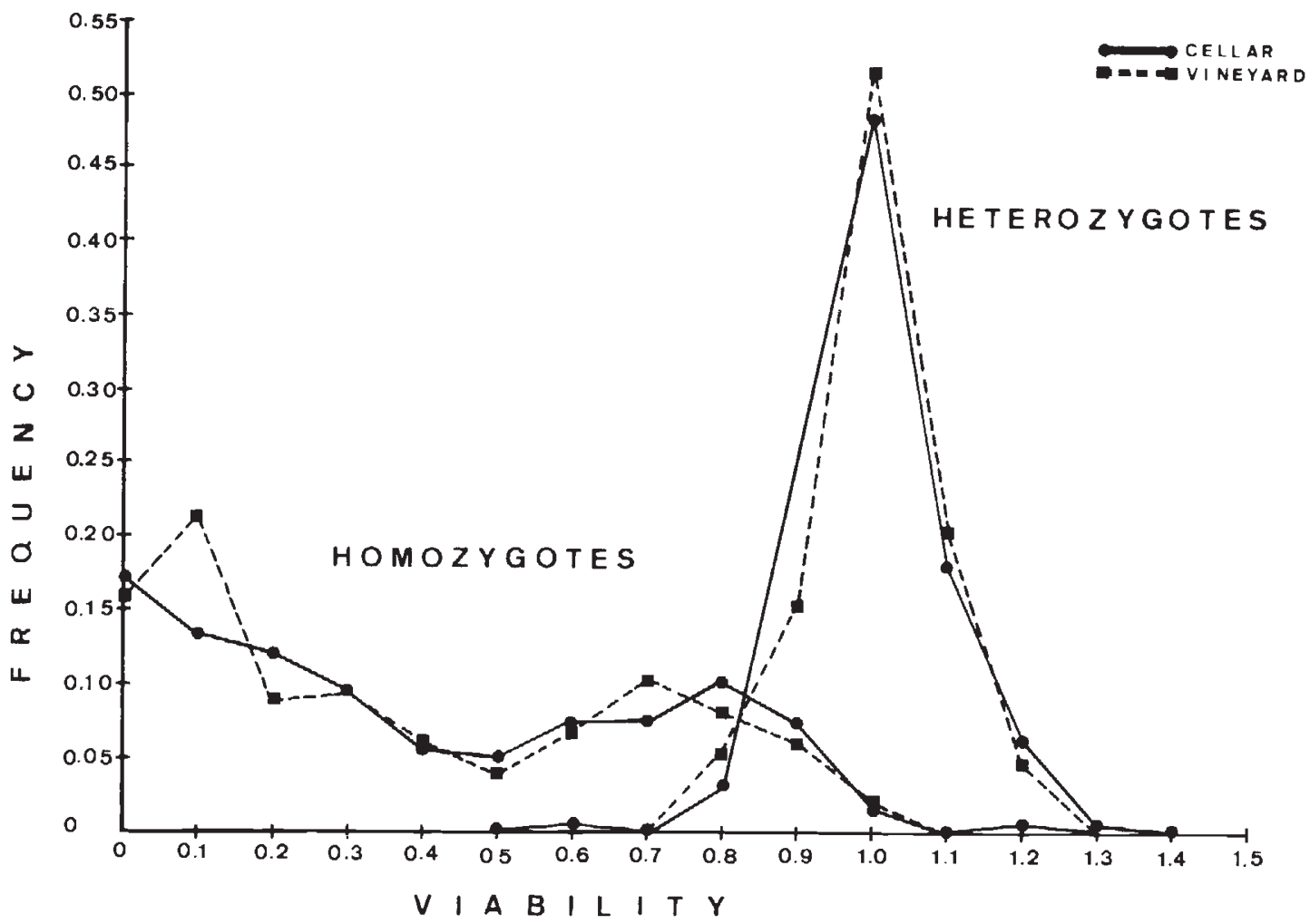

Figure 1 Frequency distributions of homozygote and heterozygote viabilities of the third chromosomes from the cellar and vineyard populations. The average viability of heterozygotes is assumed to be 1.0000 . 
Table 3 Homozygous genetic loads, expressed in lethal equivalents, for the third chromosome in cellar and vineyard populations

\begin{tabular}{llllllll}
\hline Population & Total load & D & Dm & Ds & L & Dm/L & D/L \\
\hline Cellar & 0.9146 & 0.6544 & 0.3025 & 0.3526 & 0.2602 & 1.1661 & 2.515 \\
Vineyard & 1.0003 & 0.7077 & 0.2963 & 0.4114 & 0.2926 & 1.0129 & 2.420 \\
\hline
\end{tabular}

Load components are: $\mathrm{Dm}$ for mild detrimentals (viability $>0.5$ ); Ds for severe detrimentals $(0.1<v<0.5)$ and $\mathrm{L}$ for lethals $(v<0 \cdot 1) . \mathrm{D}=\mathrm{Dm}+\mathrm{Ds}$.

homozygotes for their constituent chromosomes. On the basis of these estimated parameters, the average degrees of dominance of mildly deleterious genes in the approximately equilibrium population $\left(\bar{h}_{E}\right)$ and for newly arisen mutations $\left(\vec{h}_{N}\right)$ were estimated. The results for the vineyard population do not give any significant information due to the small sample $(n=12)$, so they were disregarded. The values estimated for the cellar population were $\hat{\hat{h}}_{E}=0 \cdot 152 \pm 0.084$ and $\hat{\hat{h}}_{N}=$ $0 \cdot 992 \pm 0 \cdot 320$.

\section{Environmental variance}

Environmental variances of viabilities of all homozygotes and heterozygotes with viability indices larger than 0.6 were estimated, using formulas (1) and (2). The environmental variance was used as an index of developmental homeostasis.

Tables $5(\mathrm{a}, \mathrm{b})$ and $6(\mathrm{a}, \mathrm{b})$ show the environmental variances for the cellar and vineyard populations and the correlation coefficient between viabilities and environmental variances. In the vineyard population, the values of the average environmental variance for homozygotes and heterozygotes are similar $(F=1 \cdot 0461 ; d f=50,144$; $0.75>p>0.5)$. In the cellar population, the average environmental variance of homozygotes is significantly smaller than those of heterozygotes $(F=1.9313 ; d f=154,64 ; p<0 \cdot 01)$.

\section{Allelism rates of lethal chromosomes and effective population size}

All lethal chromosomes from both populations were used for calculating the inter and intrapopulation allelism rates. The number of crosses made within cellar, within vineyard and between cellar and vineyard were 703,780 , and 1520 respectively; the respective rates of allelism were $0.00853 \pm$ $0.00347 ; 0.00641 \pm 0.00286$ and $0.00329 \pm 0.00147$. There are no significant differences among them.

The fraction of the lethal allelism due to mutations $\left(I_{N}\right)$ and the fraction due to consanguinity $\left(I_{F}\right)$ were estimated using the method of Wallace (1966) (table 7).

$I_{N}$ is of the same order in both populations. Therefore, the greater frequency of lethal allelism observed $\left(I_{C}\right)$ in the cellar with respect to that in the vineyard, although the difference is not significant, is principally due to the greater consanguinity of that population.

The effective sizes of both populations $(\mathrm{Ne})$ was estimated by the following formula (Nei, 1968) where the degrees of dominance of lethal genes and the mutation rates to lethals $(u)$ per locus are

Table 4 Average viabilities of: (a) lethal-free, single-lethal and double-lethal heterozygotes.

(b) semilethal-free, single-semilethal and double-semilethal heterozygotes

\begin{tabular}{|c|c|c|c|c|c|}
\hline \multicolumn{2}{|c|}{ Genotype } & \multirow{2}{*}{$\frac{N}{89}$} & \multirow{2}{*}{$\begin{array}{c}\text { Cellar } \\
\text { Average viability } \\
1.0039 \pm 0.0091\end{array}$} & \multirow{2}{*}{$\frac{N}{79}$} & \multirow{2}{*}{$\begin{array}{c}\begin{array}{c}\text { Vineyard } \\
\text { Average viability }\end{array} \\
1.0016 \pm 0.0093\end{array}$} \\
\hline (a) & Non-lethal/ Non-lethal' & & & & \\
\hline & Non-lethal/Lethal & 56 & $0.9970 \pm 0.0145$ & 51 & $1 \cdot 0099 \pm 0 \cdot 0122$ \\
\hline & Lethal/Lethal' & 10 & $0.9829 \pm 0.0161$ & 15 & $0.9648 \pm 0.0210$ \\
\hline & Total & 155 & & 145 & \\
\hline \multirow[t]{4}{*}{ (b) } & Non-semilethal/ Non-semilethal' & 29 & $1.0316 \pm 0.0170\}$ & 21 & $0.9924 \pm 0.0217$ \\
\hline & Non-semilethal/Semilethal & 39 & $0.9847 \pm 0.0129\}^{*}$ & 33 & $1.0059 \pm 0.0115$ \\
\hline & Semilethal/Semilethal' & 21 & $1.0014 \pm 0.0178$ & 26 & $1.0046 \pm 0.0171$ \\
\hline & Total & 89 & & 80 & \\
\hline
\end{tabular}

$\mathrm{N}$ stands for the number of crosses

*: $\mathrm{p}<0.05$ 
Table 5 Environmental variance for third chromosomes extracted from the cellar population

\begin{tabular}{|c|c|c|c|c|}
\hline $\begin{array}{l}\text { Viability } \\
\text { range }\end{array}$ & $\begin{array}{l}\text { No. of } \\
\text { lines }\end{array}$ & Mean viability & $\begin{array}{l}\text { Environmental } \\
\text { variance }\end{array}$ & $\begin{array}{l}\text { Average no. } \\
\text { of flies per } \\
\text { observation }\end{array}$ \\
\hline \multicolumn{5}{|c|}{ A. Homozygotes (no. of lines tested -65 ) } \\
\hline $0.5-0.6$ & 13 & $0.5441693 \pm 0.0091309$ & $0.0041751 \pm 0.0001092$ & $480 \cdot 96$ \\
\hline $0 \cdot 6-0 \cdot 7$ & 12 & $0.6402916 \pm 0.0089540$ & $0 \cdot 0054703 \pm 0 \cdot 0000953$ & $491 \cdot 17$ \\
\hline $0 \cdot 7-0 \cdot 8$ & 17 & $0.7518941 \pm 0.0064223$ & $0 \cdot 0031527 \pm 0.0002681$ & $477 \cdot 03$ \\
\hline $0.8-0.9$ & 15 & $0 \cdot 8472334 \pm 0 \cdot 00603069$ & $0.0044375 \pm 0.0002040$ & $511 \cdot 17$ \\
\hline $0 \cdot 9-1 \cdot 0$ & 7 & $0.9370714 \pm 0 \cdot 0125306$ & $0 \cdot 0030010 \pm 0 \cdot 0003250$ & $477 \cdot 29$ \\
\hline $1 \cdot 0-1 \cdot 1$ & 0 & - & - & - \\
\hline $1 \cdot 1-1 \cdot 2$ & 0 & - & - & - \\
\hline $1 \cdot 2-1 \cdot 3$ & 1 & $1 \cdot 2258000$ & -0.0050570 & $364 \cdot 00$ \\
\hline Mean & 65 & $0.7201215 \pm 0.0180210$ & $0.0039389 \pm 0.0001997$ & $486 \cdot 59$ \\
\hline $\begin{array}{r}\text { Correlatior } \\
\qquad t=-4\end{array}$ & $\begin{array}{l}\text { between } \\
71^{* * *}\end{array}$ & environmental variance & and viability $=-0.507$ & $71600 \pm 0 \cdot 1085831$ \\
\hline \multicolumn{5}{|c|}{ B. Heterozygotes (no. of crosses $=155$ ) } \\
\hline $0.6-0.7$ & 1 & 0.6141000 & -0.0025699 & $279 \cdot 50$ \\
\hline $0 \cdot 7-0 \cdot 8$ & 2 & $0.7809500 \pm 0.0012449$ & $0.0276729 \pm 0 \cdot 0024332$ & $336 \cdot 25$ \\
\hline $0.8-0.9$ & 16 & $0.8733626 \pm 0.0054588$ & $0.0095235 \pm 0.0001592$ & $546 \cdot 59$ \\
\hline $0 \cdot 9$ & 57 & $0.9556824 \pm 0.0037312$ & $0.0061584 \pm 0.0001630$ & $522 \cdot 54$ \\
\hline $1 \cdot 0-1 \cdot 1$ & 61 & $1.0405430 \pm 0.0039816$ & $0.0074841 \pm 0.0001536$ & $546 \cdot 93$ \\
\hline $1 \cdot 1-1 \cdot 2$ & 15 & $1 \cdot 1467600 \pm 0.0063123$ & $0.0107661 \pm 0.0002421$ & $545 \cdot 63$ \\
\hline $1 \cdot 2-1 \cdot 3$ & 3 & $1 \cdot 2377670 \pm 0 \cdot 0160812$ & $0.0016525 \pm 0.0004358$ & $490 \cdot 50$ \\
\hline Mean & 155 & $1.0001000 \pm 0.0075142$ & $0.0076075 \pm 0 \cdot 0002546$ & $532 \cdot 26$ \\
\hline $\begin{array}{r}\text { Correlatior } \\
\qquad t=-0\end{array}$ & $\begin{array}{l}\text { between } \\
97\end{array}$ & environmental variance & and viability $=-0.072$ & $3247 \pm 0.0806335$ \\
\hline
\end{tabular}

***: $\mathrm{p}<0.001$

the same for all loci:

$$
\hat{N} e=(1-\hat{I} g) / 4(\hat{I} g U-u)
$$

( $I g)$ stands for the allelism rate of lethal genes and can be estimated by $-\ln \left(1-I_{C} Q^{2}\right) / \ln (1-Q)^{2}$, were $\left(I_{C}\right)$ stands for the allelism rate of lethal chromosomes); $(U)$ is the total lethal mutation rate, using Wallace's (1968) estimate for the third chromosome of 0.005 .

Values of $10^{-5}$ and $0.20 \times 10^{-5}$ were used in our calculations for $(u)$; the former estimate comes from assuming that the number of lethal-producing

Table 6 Environmental variance for third chromosomes extracted from the vineyard population

\begin{tabular}{|c|c|c|c|c|}
\hline $\begin{array}{l}\text { Viability } \\
\text { range }\end{array}$ & $\begin{array}{l}\text { No. of } \\
\text { lines }\end{array}$ & Mean viability & $\begin{array}{l}\text { Environmental } \\
\text { variance }\end{array}$ & $\begin{array}{l}\text { Average no. } \\
\text { of flies per } \\
\text { observation }\end{array}$ \\
\hline \multicolumn{5}{|c|}{ A. Homozygotes (no. of lines tested -51 ) } \\
\hline $0.5-0.6$ & 8 & $0.5523000 \pm 0 \cdot 0070915$ & $0.0063380 \pm 0.0002010$ & $402 \cdot 56$ \\
\hline $0 \cdot 6-0 \cdot 7$ & 13 & $0.6594693 \pm 0.0069038$ & $0 \cdot 0059753 \pm 0 \cdot 0002404$ & $425 \cdot 88$ \\
\hline $0 \cdot 7-0 \cdot 8$ & 15 & $0.7636667 \pm 0.0063457$ & $0.0066335 \pm 0.0003222$ & $463 \cdot 13$ \\
\hline $0.8-0 \cdot 9$ & 8 & $0.8483876 \pm 0.0114843$ & $0.0223759 \pm 0.0003783$ & $482 \cdot 94$ \\
\hline $0 \cdot 9-1 \cdot 0$ & 5 & $0.9244200 \pm 0.0085386$ & $0.0081152 \pm 0.0006848$ & $410 \cdot 90$ \\
\hline $1 \cdot 0-1 \cdot 1$ & 2 & $1.0327000 \pm 0.0089902$ & $0.0012345 \pm 0.0001093$ & $593 \cdot 00$ \\
\hline Mean & 51 & $0 \cdot 7435510 \pm 0 \cdot 0181040$ & $0.0088223 \pm 0.0008551$ & $477 \cdot 20$ \\
\hline \multicolumn{5}{|c|}{$\begin{array}{l}\text { Correlation between environmental variance and viability }=0.3113898 \pm 0 \cdot 1357546 ; t=2 \cdot 294 * \\
\text { B. Heterozygotes ( } \text { no. of crosses }=145 \text { ) }\end{array}$} \\
\hline $0 \cdot 7-0 \cdot 8$ & 3 & $0.7882667 \pm 0.0029263$ & $0 \cdot 0152445 \pm 0 \cdot 0000308$ & $544 \cdot 17$ \\
\hline $0.8-0.9$ & 14 & $0 \cdot 8641358 \pm 0 \cdot 0069368$ & $0.0071703 \pm 0.0004218$ & $457 \cdot 07$ \\
\hline $0 \cdot 9-1 \cdot 0$ & 51 & $0.9598254+0.0041240$ & $0.0080180 \pm 0.0001152$ & $526 \cdot 36$ \\
\hline $1 \cdot 0-1 \cdot 1$ & 61 & $1 \cdot 0371180 \pm 0 \cdot 0036184$ & $0.0076714 \pm 0.0001144$ & $532 \cdot 88$ \\
\hline $1 \cdot 1-1 \cdot 2$ & 14 & $1 \cdot 1336500 \pm 0 \cdot 0083707$ & $0.0146242 \pm 0.0003869$ & $471 \cdot 39$ \\
\hline $1 \cdot 2-1 \cdot 3$ & 2 & $1 \cdot 2289500 \pm 0 \cdot 0180433$ & $-0.0024201 \pm 0.0009576$ & $431 \cdot 50$ \\
\hline Mean & 145 & $1.0001011 \pm 0.0070112$ & $0.0084337 \pm 0.0002317$ & $516 \cdot 16$ \\
\hline
\end{tabular}

$*: p<0.05$ 
Table 7 Estimate of the lethal allelism due to chance mutations and consanguitnity

\begin{tabular}{llll}
\hline & $\mathrm{I}_{\mathrm{C}}$ & $\mathrm{I}_{\mathrm{N}}$ & $\mathrm{I}_{\mathrm{F}}$ \\
\hline $\begin{array}{llll}\text { VINEYARD } \\
\mathbf{n}=500\end{array}$ & & 0.0027 & 0.0037 \\
$\mathbf{n}=2400$ & 0.0064 & 0.00057 & 0.0058 \\
CELLAR & & & \\
$\mathbf{n}=500$ & 0.0085 & 0.0026 & 0.0059 \\
$\mathbf{n}=2400$ & & 0.00055 & 0.0079 \\
\hline
\end{tabular}

$I_{C}=$ Rate of lethal allelism observed; $I_{N}=$ lethal allelism due to mutation; $I_{F}=$ allelism due to consanguinity; $n=$ no. of lethal producing loci per third chromosome.

loci per third chromosome is similar to the second chromosome, $n=500$ (cf. Wallace, 1950) and the latter is based on $n=2,400$ (Judd et al., 1972).

The estimate of effective sizes for both populations are presented in table 8 .

Table 8 Estimates of the effective population sizes for cellar and vineyard populations

\begin{tabular}{lcl}
\hline Population & Cellar & Vineyard \\
\hline $\mathrm{Q}$ & 0.2452 & 0.2759 \\
$\mathrm{I}_{\mathrm{C}}$ & 0.0085 & 0.0064 \\
$\mathrm{I}_{\mathrm{g}}$ & 0.0065 & 0.0047 \\
$\mathrm{~N}_{\mathrm{e}}: \mathrm{u}=10^{-5}$ & 11000 & 18500 \\
$\quad \mathrm{u}=0 \cdot 2 \times 10^{-5}$ & 8000 & 11500 \\
\hline
\end{tabular}

$\mathrm{Q}=$ Frequency of lethal chromosomes; $\mathrm{I}_{\mathrm{C}}=$ allelism rate of lethal chromosomes; $I_{B}=$ allelism rate of lethal genes; $N_{c}=$ effective population size; and $u=$ lethal mutation rate per locus

\section{DISCUSSION}

The frequency distributions of homozygote and heterozygote viabilities of Drosophila melanogaster from cellar and vineyard populations are similar, in spite of their habitats being relatively different. Factors peculiar to the cellar do not influence the fitness of its population of D. melanogaster (at least, as regards viability, which is the component of fitness studied here).

In the cellar population, the lethals in the heterozygous condition show a very slight deleterious effect while in the vineyard population neither dominance nor overdominance is manifest. Detrimental heterozygous effect of lethal genes in our populations can also indirectly be estimated from the frequency of lethal-carrying chromosomes. Under the null hypothesis (that heterozygous lethal genes are not deleterious to their carriers), the equilibrium frequency of lethalcarrying chromosomes can be predicted. The equilibrium frequency of a lethal is $(u)$ (where $(u)$ is the lethal mutation rate). If the number of lethalproducing loci is $(n)$, then the average number of lethal genes per chromosome is $n \sqrt{u}$. Assuming that the lethal genes are distributed on the chromosome according to a Poisson distribution, the expected frequency of lethal-cerrying chromosomes $(Q)$ can be estimated to be: $E(Q)=$ $1-e^{-n \sqrt{ } u}$.

Values of $(u)$ and $(n)$ have been reported as $10^{-5} /$ locus/generation and 500 respectively (as a minimum estimate); thus, $E(Q)=0.79$. If $n=$ 2,400 ; then $E(Q)=0.97$. The estimates of $(Q)$ in our populations are 0.24 and 0.27 , which are sig. nificantly smaller than the minimum estimate of 0.79 . This finding rejects the null hypothesis and clearly supports the alternative hypothesis that the fitness of lethal heterozygotes is significantly smaller than of lethal-free individuals in both habitats (cf. Mukai and Yamaguchi, 1974; Mukai and Nagano, 1983).

The semilethals in heterozygous condition in both populations show the same behaviour as the lethals and the average degree of dominance of viability polygenes estimated in the cellar population, though it is low $\left(\vec{h}_{E}=0.152\right)$ is within the estimated values for natural populations of Drosophila melanogaster made by Mukai (1969) and close to the estimates of Mukai (1964) and Mukai and Yamaguchi (1974).

Which mechanisms may act to maintain genetic load and genetic variability of viability in these populations?

Such a high detrimental load might indicate that some type of balancing selection is acting at some loci. However, heterosis was not observed for lethals nor for detrimentals, which together with the slight rate of lethal allelism, does not support associative overdominance as a mechanism operating to maintain these deleterious genes.

Simmons et al., (1980) observed pleiotropic effects on fitness of mutations affecting viability in D. melanogaster. However, our experimental results do not support the action of associative overdominance on other components of fitness. Also, the experiments of Marinkovic (1967) and Rose and Charlesworth (1981) indicate no overdominance with respect to fertility.

The estimated values for elimination rates of lethals due to homozygosity depend on $I Q^{2}[(Q)$ being the frequency of lethal-carrying chromosomes and $(I)$ their allelism rate $]$ and were 0.00050 and 0.00048 for the cellar and vineyard respectively. These values are much smaller than the average chromosome mutation rate $(0.0005)$ established by Wallace (1968) for the third chromosome. 
Therefore, in our populations, bearing in mind that selective neutrality of the lethal heterozygotes has been rejected, purifying selection must be acting, (although at a low intensity) to eliminate lethals through heterozygotes.

Dominance (Mukai et al., 1974; Mukai et al., 1980; Mukai et al., 1982b; Tachida and Mukai, 1985) or frequency dependent selection (Dolan and Robertson, 1975; Yoshimaru and Mukai, 1979) are not satisfactory mechanisms for maintaining genetic variability in random mating populations: diversifying selection may be a better candidate. However, the present study does not support the view that this type of selection is acting in our populations. In the vineyard, differences in the environmental variances of viability between homozygotes and heterozygotes is not observed; while in the cellar, developmental homeostasis for viability is manifested in heterozygotes even more than in homozygotes. This is different from the results in the Raleigh (Mukai et al., 1982), the Florida (Mukai and Nagano, 1983) and the Ishigakijima (Tachida and Mukai, 1985) populations. The vineyard population is more similar, as regards the environmental variances of viability, to the Japanese population of Aomari studied by Kusakabe and Mukai (1984a) showing a rather similar situation to that of the newly arisen mildly deleterious mutations, which have not experienced natural selection at all (Mukai et al., 1982a).

The smaller environmental variance of homozygotes compared to that of heterozygotes in the cellar population might simply result from the higher endogamy of this population, a circumstance which induce homozygosis. As the stability in viability of heterozygotes over homozygotes is a product of natural selection (Mukai et al., 1982a), if this selection is not positively acting on the newly arisen mildly detrimental mutations which are homeostatic in heterozygotes, or if the selection pressure is very low, the gene frequency of homozygously homeostatic genes increases in this population. Thus, we find homozygote stability in respect of the viability in the chromosomes from the cellar population.

Recent work (Mukai et al., 1974; Mukai and Nagano, 1983; Tachida et al., 1983; Kusakabe and Mukai, 1984b) suggest that the principal mechanism responsible for the maintenance of genetic variability of viability on the majority of loci in the natural populations is likely to be a mutationselection balance. These works also indicate that is a north-to-south cline in the magnitude of genetic variability of viability, which suggests that selection operates more actively in southern popu- lations. If the high detrimental load in the populations from cellar and vineyard indicates the existence of a great number of concealed deleterious genes in our populations, then their behaviour would be more similar to that of more southern Japanese and American populations, where selection is more active. However, in our populations, the deterimental load is even higher than that of such southern populations.

The lethal load from the cellar and vineyard populations is within the range of that of natural populations (e.g., Greenberg and Crow, 1960; Kusakabe and Mukai, 1984a). The frequencies of lethal-carrying chromosomes in our populations are similar to the frequencies observed for this species in Mediterranean populations (Golschmidt et al., 1955; Dawood, 1961; Sperlich and Karlik, 1963; Mourad et al., 1976). Nevertheless, our values for the $D: L$ relation are higher than those estimated in natural populations for $D$. melanogaster, and are closer to the values of other Drosophila species (Dobzhansky and Spassky, 1953; Malogolowkin-Cohen et al., 1964).

What could be the cause of the high detrimental load in the populations studied? We think that two circumstances may be present: a higher mutation rate of mildly deleterious genes compared to that of lethals, the normal ratio of 20:1 (Mukai, 1964), and very low average degrees of dominance of lethals and detrimentals compared to that of the majority of natural populations, the difference being relatively more accentuated for the average degree of dominance of detrimental genes. Therefore, the elimination by selection through heterozygotes will be low, more particularly for detrimentals; the accumulation of these will hence be higher.

The possible effect of newly induced mutations in the processes of establishment and maintenance of chromosome lines might also be considered (Mukai, 1964; Mukai et al., 1972). However the means and the variances in the different sets of experiments (cycles) did not decrease or increase as the experiments advanced, suggesting that this effect is not important.

It is unlikely that estimated viabilities are disturbed as a consequence of recombinational phenomena in $U b x /+$ heterozygous females due to the TM2 balancer (McIntyre and Wright, 1966). This chromosome also carry out the $h$ and $c a$ mutations which were used as a control, and no recombination was observed in any of the lines analysed. Moreover, this phenomenon occurred when the $U b x /+$ females also were heterozygous for an X-chromosome inversion. In natural popu- 
lations of $D$. melanogester, inversions on the $\mathrm{X}$ chromosome are rare (Inoue et al., 1984) and, in our populations no inversion has been detected on this chromosome (González, 1985).

We cannot reject out the chromosome cytoplasmic interaction known as hybrid dysgenesis (Kidwell et al., 1977). If this were present during the extraction of the third chromosome, the homozygous load due to detrimental genes estimated in the present study might be overestimated. However in a study on male recombination in the same populations (Botella and Ménsua, 1983), male recombination frequencies typical of hybrid dysgenesis were not detected.

The high detrimental load may exist in our populations throughout the year, but can also be a circumstance due to the moment of capture, which was at the end of the seasonal cycle of $D$. melanogaster. There might be a higher frequency of deterimental genes then due to their accumulation over the seasonal, as a consequence of the low pressure against detrimental heterozygotes.

The fact that cellar and vineyard populations behave in the same way suggest that they are subpopulations of a large population.

Lethal allelism and the population size estimate support this supposition. Wallace (1966) and Paik (1968) observed that the frequency of allelism of lethals declines linearly with the square root of distance. However, for the relatively great distance that separates the cellar and the vineyard $(4 \mathrm{Km})$ the rate of allelism although it decreases does not do so markedly. The effective population sizes estimated in the cellar and vineyard populations are not very different; both populations are relatively large and the smaller size estimated in the cellar is essentially due to the consanguinity of this population (as suggested by the lethal allelism due to endogamy).

However, the level of interpopulational allelism of lethals is very low suggesting that each population has a characteristic complement of lethals. This indicates a certain independence of the two populations, which calls into question whether they really are two subpopulations of a larger population.

We think, in spite of the low frequency of interpopulation allelism, that there is gene flow between cellar and vineyard. McKenzie and Parsons (1974) observed in the D. melanogaster population from "Chateau Tahbilk", the existence of genic flow between the cellar and the exterior. Jones et al. (1981) estimated migration for $D$. pseudoobscura and their work suggests that migration between populations to the extent inferred here is quite feasible. Moreover, it must be taken into account that the frequencies of interpopulation allelism are not excessively low if they are compared with the frequency of intrapopulation allelism and as Spieth (1974) said, "in terms of gene flow, the distinction between absolutely none and almost none is enormous".

\section{REFERENCES}

BOtella, L. M. AND mensuA, J. L. 1983. Analysis of male recombination in third chromosomes of Drosophila melanogaster. Genetica, 61, 197-203.

CHOI, Y, 1978. Genetic load and viability variation in Korean natural populations of Drosophila melanogaster. Theor. Appl. Genet., 53, 65-70.

DAwOOD, M. M. 1961. The genetic load in the second chromosomes of some populations of Drosophila melanogaster. Egypt Genetics, 46, 239-246.

DOBZHANSKY, T. AND SPASSKY, B. 1953. Genetics of natural populations. XXI. Variability in two sympatric species of Drosophila. Genetics, 38, 471-484.

DOLAN, R. AND ROBERTSON, A. 1975. The effect of conditioning the medium in Drosophila, in relation to frequencydependent selection. Heredity, 35, 311-316.

GOLDSCHMIDT, E., WAHRMAN, J., LEDERMANN-KLEIN, A. AND WEISS, R. 1955. A two years survey of population dynamics of Drosophila melanogaster. Evolution, 9, 353366.

GONZalez, A. 1985. Ph.D. Thesis, University of Valencia.

GREENBERG, R. AND CROW, C. F. 1960. A comparison of the effect of lethal and detrimental chromosomes from Drosophila populations. Genetics, 45, 1154-1168.

HALDANE, J. B. J. 1956. Estimation of viabilities. J. Genetics, 54, 294-296.

INOUE, Y., WATANABE, T. AND WATANABE, T. K. 1984. Evolutionary change of the chromosomal polymorphism in Drosophila melanogaster populations. Evolution, 38, 753-765

JONES, J. S., BRYANT, S. H., LEWONTIN, R. C., MOORE, J. A. AND PROUT, T. 1981. Gene flow and the geographical distribution of a molecular polymorphism in Drosophila pseudoobscura. Genetics, 98, 157-178.

JUDD, B. H., SHEN, M. W. AND KAUFMAN, T. C. 1972. The anatomy and function of a segment of the $\mathrm{Y}$ chromosome of Drosophila melanogaster. Genetics, 71, 139-156.

KIDWELL, M. G., KIDWELL, J. F. AND SVED, J. A. 1977. Hybrid dysgenesis in Drosophila melanogaster: a syndrome of aberrant traits including mutation, sterility and male recombination. Genetics, 86, 813-833.

KUSAKABE, S. AND MUKAI, T. 1984a. The genetic structure of natural populations of Drosophila melanogaster. XVII. A population carrying genetic variability expliciable by the classical hypothesis. Genetics, 108, 393-408.

KUSAKABE, S. AND MUKAI, T. 1984b. The genetic structure of natural populations of Drosophila melanogaster. XVIII Clinal and uniform genetic variation over populations Genetics, 108, 617-632.

LEVENE, H. 1953. Genetic equilibrium when more than one ecological niche is available. Amer. Nat., 87, 331-333.

LEVINS, R. 1968. Evolution in changing environments. Princeton Univ. Press. Princeton. 
LEVINS, R. AND MCARTHUR, R. 1966. Maintenance of genetic polymorphism in a heterogeneous environment: variations on a theme by Howard Levene, Amer. Nat., 100, 580-590.

MALOGOLOWKIN-COHEN, C., LEVENE, H., DOBZHANSKY, N. P. AND SIMMONS, A. S. 1964. Inbreeding and the mutational and balanced loads in natural populations of a Drosophila willistoni. Genetics, 50, 1299-1311.

MARINKOVIC, D. 1967. Genetic loads affecting fecundity in natural populations of Drosophila pseudoobscura. Genetics, $56,61-71$.

MCINTYRE, R. J. AND WRIGHT, T. R. F. 1966. Recombination in FM4/+; SM1/+; Ubx $x^{130} /+$ heyterozygotes. Dros. Inf. Serv., 41, 141-142.

McKENZIE, J. A. AND PARSONS, P. A. 1974. Microdifferentiation in a natural population of Drosophila melanogaster to alcohol in the environment. Genetics, 77, 385-394.

MOURAD, A. H., TANTAWY, A. D. AND MOSTAGA, Y. A. 1976. Studies on natural populations of Drosophila. XIX. Concealed genetic variability in a marginal population of Drosophila melanogaster and its fate under laboratory conditions. Egypt. J. Genet. Cytol., 5, 346-358.

MUKAI, T. 1964. The structure of natural populations of Drosophila melanogaster. I. Spontaneous mutation rate of polygenes controlling viability. Genetics, 50, 1-19.

MUKAI, T. 1969. The genetic structure of natural populations of Drosophila melanogaster. VIII. Natural selection on the degree of dominance of viability polygenes. Genetics, 63, 467-478.

MUKAI, T, AND NAGANO, S. 1983. The genetic structure of natural populations of Drosophila melanogaster. XVI. Excess of additive genetic variance of viability. Genetics, $105,115-134$.

MUKAI, T. ANI) YAMAGUCHI, D. 1974. The genetic structure of natural populations of Drosophila melanogaster. XI. Genetic variability in a local population. Genetics, 76, 339-366.

MUKAI, T., CHIGUSA, S. I., METTLER, L. E. AND CROW, J. F. 1972. Mutation rate and dominance of genes affecting viability in Drosophila melanogaster. Genetics, 72, 335-355.

MUKAI, T, C.AR DELLINO, R. A., WATANABE, T. K. AND C:ROW, J. F. 1974. The genetic variance for viability and its components in a local population of Drosophila melanogaster. Genetics, 78, 1195-1208.

MUKAI, T., TACHIDA, H. AND ICHINOSE, M. 1980. Selection for viability at loci controlling protein polymorphisms in Drosophila melanogaster is very weak at most. Proc. Nat. Acad. Sci. (USA), 77, 4857-4860.
MUKAI, T., (:HIGUSA, S. I. AND KUSAKABE, S. 1982a. The genetic structure of natural populations of Drosophila melanogaster. XV. Nature of developmental homeostasis for viability. Genetics, 101, 279-300.

MUKAI, 'T., YAMAGUC $H I$, ( $)$, KUSAKABE, S., TACHIDA, H. MATSUDA, M., ICHINOSE, M. ANI YOSHIMARU, H. 1982b. Lack of balancing selection for protein polymorphisms. Kimura, M. (ed.), in Molecular evolution, protein polymorphisms and the neutral theory, Japan Scientific Societies Press, Tokyo/Springer-Verlag, Berlin.

NEI, M. 1968. The frequency distribution of lethal chromosomes in finite populations. Proc. Nat. Acad. Sci. (USA), 60, $517-524$

PAIK, Y. K. 1968. Behaviour of lethals in Drosophila melanogaster. Proc. XII Intern. Congr. Genet., 2, 164-165.

ROSE, M. R. ANI) CHARLESWORTH, B. 1981. Genetics of life history in Drosophila melanogaster. I. Sib analysis of adult females. Genetics, 97, 173-186.

SIMMONS, M. J., PRESON, C. R. AND ENGELS, W. R. 1980 Pleiotropic effects on fitness of mutations affecting viability in Drosophila melanogaster. Genetics, 94, 467-475.

SPERLICH, D. AND KARLIK, A. 1963. Frequenz und Alleliegrad autosmaler Letalfaktoren in Insel-und Festlandspopulationen von Drosophila melanogaster. Verh. Deutsch. Zool. Ges. Munchen, 73-78.

SPIETH, P. 1974. Gene flow and differentiation. Genetics, 78, 961-965.

TACHIDA, H. AND MUKAI, T. 1985. The genetic structure of natural populations of Drosophila melanogaster. XIX. Genotype-environment interaction in viability, Genetics, $111,43-55$.

TACHIDA, H., MATSUDA, M., KUSAKABE, S. AND MUKAI, T. 1983. Variance component analysis for viability in an isolated population of Drosophila melanogaster. Genet. Res. Camb., 42, 207-217.

WALLACE, B. 1950. Allelism of second chromosome lethals in Drosophila melanogaster. Proc. Nat. Acad. Sci. (USA), 36, 654-657.

WALLAC:E, B. 1966. Distance and the allelism of lethals in a tropical population of Drosophila melanogaster. Amer. Nat., 100, 565-578.

WALLACE, B. 1968. Mutation rates for autosomal lethals in Drosophila melanogaster. Genetics, 60, 389-393.

YOSHIMARU, H. AND MUKAI, T. 1979. Lack of experimental evidence for frequency-dependent selection at the alcohol deshydrogenase locus in Drosophila melanogaster. Proc. Nat. Acad. Sci. (USA), 76, 876-878 